\title{
Desigualdade e legitimidade \\ Problematizando a produção de conhecimento social
}

\author{
Teresa Pires do Rio Caldeira* \\ https://orcid.org/0000-0002-7737-7522
}

\begin{abstract}
It seems to me curious, not to say obscene and thoroughly terrifying, that it could occur to an association of human beings drawn together through need and chance and for profit into a company, an organ of journalism, to pry intimately into the lives of an undefended and appallingly damaged group of human beings, an ignorant and hopeless rural family, for the purpose of parading the nakedness, disadvantage and humiliation of these lives before another group of human beings, in the name of science, of "honest journalism" (whatever that paradox may mean), of humanity, of fearlessness, for money, and for a reputation. James Agee \& Walker Evans, [1941] 1969, p. 7.
\end{abstract}

Em 1936, em plena grande depressão, James Agee e Walker Evans foram enviados pela revista Fortune ao Alabama, no sul dos Estados Unidos, para documentar as condiçôes de vida dos pequenos agricultores produtores de algodão. As imagens produzidas pelo fotógrafo Walker Evans são das mais icônicas representações de extrema pobreza que conhecemos. Em Let us now praise famous men, quarenta dessas fotos aparecem antes mesmo do título do livro e servem como contexto à poderosa abertura do Livro um, que se inicia com a citação acima. As fotos não devem ser tomadas como ilustração, advertem os autores, mas elas e o texto devem ser considerados como "coequal, mutually independent, and fully collaborative" $(\mathrm{xv})^{1}$. Tanto o texto quanto as fotos acabaram sendo vetados pela revista e só foram publicados sob a forma de livro anos mais tarde. Let us now praise famous men

* Universidade da Califórnia, Berkeley, Estados Unidos.

1. "Co-iguais, mutuamente independentes e completamente colaborativos." 
continua sendo um dos mais poderosos experimentos de jornalismo/etnografia produzidos no século xx. Eram muitas as dúvidas de James Agee sobre seu papel como jornalista e investigador da vida dos pobres camponeses desprovidos de quase tudo. Suas reflexões, escritas para serem lidas em voz alta e numa prosa modernista que parece ter alienado muitos, se estendem por inúmeras páginas e nunca falham em fazer os leitores se sentirem desconfortáveis ao lerem esse livro, que apesar de tudo ele escreveu e nós temos em nossas mãos. Leitores-cúmplices dos dilemas éticos do autor e consumidores da pobreza estetizada tanto pelas fotos quanto pelo texto, malgrado os esforços de distanciamento crítico dos autores. As dúvidas agudas são seguidas por quase quatrocentas páginas de uma etnografia minuciosa de três famílias camponesas em que as mais diversas dimensões de suas vidas, especialmente suas casas, seus parcos objetos e seu mais do que precário cotidiano, são descritos e fotografados em detalhe. O objetivo não é tanto documentar a pobreza extrema, mas tentar resgatar em cada detalhe a humanidade dessas famílias e a intensa existência de cada elemento, humano ou material ${ }^{2}$.

Esse poderoso livro - as reflexões desconcertantes de Agee, as imagens de Evans, o experimento de sua associação e a delicadeza da análise do cotidiano têm me acompanhado por mais de quarenta anos. Usei essa mesma epígrafe num dos primeiros artigos que publiquei, "Uma incursão pelo lado 'não respeitável' da pesquisa de campo", em 1981. Volto a ela porque acho que muitas das questões e dos dilemas levantados por Agee, refletidos por mim desde meu primeiro trabalho de campo, e por muitos antropólogos especialmente desde a publicação de Writing culture em 1986, continuam não resolvidos e exigindo nossa reflexão, sobretudo dadas as inúmeras mudanças que ocorreram na prática da pesquisa em ciências sociais nesse período (Clifford \& Marcus, 1986). Essas questôes e dilemas dizem respeito à maneira pela qual se produzem pesquisas sociais, sobretudo em situações marcadas por grandes desigualdades. Dizem também respeito à questão de como conceber as representaçôes dos achados dessas pesquisas e a autoria. Finalmente, concernem às possibilidades de circulação dos discursos. Essas questões constituem, portanto, um espaço de problematização, no sentido que Foucault e Rabinow conferem a essa noção:

O traço definidor da problematização não é a conexão de opostos (fora ou dentro, livre ou constrangido), mas sim o tipo de relação forjada entre observador e situação problematizada. A especificidade dessa relação implica tomar a situação simultaneamente como problemática e como algo sobre o qual se é obrigado a pensar (Rabinow 2002, p. 139) ${ }^{3}$.

2. Nesse sentido, ver o ensaio de Denby (2006) sobre a obra de Agee.

3. "The defining trait of problematization does not turn on the couplings of opposites (outside or inside, 
Imagino que possa tomar como consensual que a noção de neutralidade na produção de conhecimentos em ciências sociais (e não só nelas) já foi suficientemente questionada e descontruída, e que a ideia de que verdades são efeitos de poder, inicialmente articulada por Foucault $(1979,1980)$, também já seja bastante conhecida e aceita. Além disso, os mecanismos discursivos e institucionais que sustentaram a legitimidade dessas noções expressas na ênfase na objetividade científica são bem $\operatorname{conhecidos}^{4}$. Na antropologia, esses mecanismos criaram uma configuração do que seria o procedimento objetivo e científico: o cientista seria o pesquisador de campo (em contraste com o pesquisador de gabinete); seu método, a observação participante; seu objeto, culturas entendidas como totalidades discretas; o modo de representação, o realismo etnográfico escrito sincronicamente no tempo presente e pretendendo expressar o "ponto de vista nativo".

A antropologia sempre ocupou uma posição ambígua nas discussões sobre cientificidade, mas nem por isso deixou de legitimar a ênfase na neutralidade e na objetividade 5 . A ambiguidade da antropologia vem do fato de que, ao contrário do que acontece em outras ciências e mesmo nas outras ciências sociais, em que o analista e pesquisador procura o mais possível estar ausente da análise e da exposição dos dados, como meio de garantir uma posição neutra e objetiva legitimadora da cientificidade, o antropólogo nunca esteve ausente de seu texto e da exposição de seus dados. Ao contrário: produtor ele mesmo de seus dados, instrumento privilegiado de pesquisa, a presença do antropólogo profissional tanto no trabalho de campo quanto no texto etnográfico foi essencial para a constituição do conhecimento antropológico. Baseando a sua produção de conhecimento na experiência pessoal de uma outra cultura, a antropologia legitimou seus enunciados na fórmula: "eu estive lá, vi e, portanto, posso falar sobre o outro". Nessa fórmula se assentou a construção da autoridade etnográfica (Clifford, 1983).

Mas que tipo de presença é essa? Seguramente não é o mesmo tipo de presença do escritor que cria textos literários de ficção. A ficção antropológica (Geertz, 1973, cap. 1) teve algumas características peculiares: ela pretende, de uma maneira objetiva

free or constrained), but rather on the type of relationship forged between observer and problematized situation. The specificity of that relationship entails taking up the situation simultaneously as problematic and as something about which one is required to think".

4. Ver Poovey (1998, especialmente cap. 2) para uma análise brilhante da origem do que ela chama de fato social e sobretudo dos argumentos que afirmam a neutralidade científica nas ciências sociais.

5. Analisei a questão da objetividade na antropologia e a ambiguidade de suas produções textuais em "A presença do autor e a pós-modernidade na antropologia” (Caldeira, 1988). Os próximos parágrafos desta seção, com algumas atualizações, vêm diretamente desse texto. 
(científica, diriam alguns), fazer a ponte entre dois mundos culturais, revelando para um deles uma outra realidade que só o antropólogo, este sujeito que experimenta e traduz, conhece. Presença ambígua, portanto, que precisa, ao mesmo tempo, mostrar-se (revelando a experiência pessoal) e esconder-se (garantindo a objetividade). Essa ambiguidade foi por muito tempo a marca da presença de antropólogos nos seus textos.

Nos anos 1980, essas noções foram agudamente criticadas por uma geração de antropólogos que acabou sendo identificada com a publicação do livro Writing culture (Clifford \& Marcus, 1986), embora a elaboração da crítica tenha sido bem mais ampla do que o que aparece nesse volume. Essa crítica colocou uma grande ênfase na produção de textos e nas práticas de autoria, e articulou alguns pontos básicos. Primeiro, argumentou que a presença do autor nos textos etnográficos era excessiva. Na verdade, seria a única presença real nos textos, ainda que ocultada. Ela apagaria as vozes, as interpretações, os enunciados daqueles sobre quem fala. Na melhor das hipóteses, seria uma presença que subsume tudo à sua própria voz. O outro só existiria pela voz do antropólogo que esteve lá, viu e reconstruiu a cultura nativa enquanto totalidade em seu texto. Essa ideia bastante pretensiosa é emblematicamente expressa por Malinowski em seu diário:

Sentimento de propriedade: sou eu que vou descrevê-los ou cria-los [...] Esta ilha, apesar de não ter sido "descoberta" por mim, é pela primeira vez experimentada artisticamente e dominada intelectualmente (Bronislaw Malinowski, 1917, citado por Stocking 1983, p. 101) ${ }^{6}$.

Assim, a presença excessiva dos antropólogos corresponderia a uma ausência: a do questionamento sobre a sua inserção no campo, no texto e no contexto em que escrevem. Por isso, a mesma crítica vai acrescentar: presença insuficiente. Na verdade, presença insuficientemente crítica a respeito de si mesma, a respeito de seu papel na produção de representações; presença que tende a ignorar que o conhecimento antropológico se produz, de um lado, em um processo de comunicação, marcado por relações de desigualdade e poder, e, de outro, em relação a um campo de forças que define os tipos de enunciados que podem ser aceitos como verdadeiros. As desconcertantes dúvidas de Agee nunca figuraram nas discussões da antropologia clássica, apesar das patentes desigualdades que moldaram a produção de conhecimento cultural no contexto colonial.

Os efeitos das várias versões dessa crítica à antropologia elaborada desde o final dos anos 1970 foram significativos. Entre eles, está um deslocamento do papel do

6. "Feeling of ownership: it is I who will describe them or create them [...]. This island, though not 'discovered' by me, is for the first time experienced artistically and mastered intellectually". 
autor e da autoridade etnográfica (ver Caldeira, 1988): o antropólogo não se encontra mais numa situação privilegiada para a produção de conhecimento cultural. É um entre outros produtores de significado. $O$ texto não deve articular a sua voz (mesmo que dissimulada), mas deve "dar preeminência à intersubjetividade de toda fala e ao seu contexto performativo imediato" (Clifford, 1983, p. 133). O modelo que se propõe para o texto é o da polifonia. Foram muitos os experimentos textuais que se seguiram tentando explorar essa intuição e sobre os quais não poderei comentar aqui, mas já analisei em outra ocasião (Caldeira, 1988).

Foram muitas também as reflexões sobre como conceber a produção do conhecimento no trabalho de campo. Uma de suas primeiras versões foi o livro Reflections on fieldwork in Morocco, de Paul Rabinow, publicado em 1977. Como era a norma na época, ele tinha ido ao Marrocos em 1968 para "se transformar num antropólogo" (p. 1). Suas reflexões mantinham a separação clara entre culturas e ainda tratavam a pesquisa sobre a cultura marroquina como um encontro com o "outro". Mas esse encontro é bastante problematizado. O principal problema que interessava a Rabinow ao refletir sobre seu trabalho no Marrocos era: quais são as maneiras pelas quais um antropólogo e seus interlocutores constroem significado e dados em interações contextualizadas por grandes desigualdades e diferenças sociais? Sua resposta é construtivista e põe de lado qualquer perspectiva positivista que supusesse que a realidade já estivesse lá pronta para ser captada. Essa construção é difícil e parcial, mas possível. Ela requer a intenção de escutar e um trabalho árduo de ambos os lados, mas gera entendimento e processos mútuos de transformação. Ela definitivamente requer atenção constante - especialmente no processo da escrita - às maneiras pelas quais essa comunicação foi moldada e, portanto, configurou o que acabaram sendo os dados ${ }^{7}$.

Apesar das muitas mudanças cruciais na prática da pesquisa antropológica, provocadas por Writing Culture e as discussões que gerou, ainda há muitas questões que não foram tocadas, especialmente no que diz respeito ao trabalho de campo. Como argumentou Rabinow no prefécio de 2007 para a edição celebrando o trigésimo aniversário da publicação de Reflections on fieldwork in Morocco:

A mim parecia que o fetiche da etnografia e do trabalho de campo tinha permanecido mais ou menos em vigor. A questão de quem era autorizado a falar e quais formas aquela fala (e sua transformação escrita) deveria ter poderia ter movido a discussão em direções poten-

7. Em Caldeira, 2021, discuto as análises de Rabinow sobre o trabalho de campo no Marrocos e apresento alguns argumentos sobre as mudanças nas condições do trabalho etnográfico nos últimos trinta anos. Algumas dessas questões já tinham sido tratadas em Caldeira, 1981. 
cialmente importantes. Mas, infelizmente, ela tendeu a fornecer uma plausibilidade naive à subjetividade e ao final não gerou os dividendos transformadores que tinham sido antecipados e anunciados. De uma maneira bem americana, a atenção ao sujeito do conhecimento virou uma série de debates confessionais sobre o "self", precisamente no momento em que parecia que o desafio era inventar modos de pensamento e de pesquisa que, apesar de não serem positivistas, buscassem maneiras de criar um processo de ir além do (dado) self ${ }^{8}$ (Rabinow, 2007, pp. xviii-xix).

Em suma, esses experimentos textuais e os questionamentos sobre o trabalho de campo acabaram se voltando para questões de subjetividade e não contemplando as questões de Agee, que focalizavam antes de mais nada grandes desigualdades sociais e de poder que moldam o processo de produção de conhecimento. Ensaiei uma consideração sobre essas questões no artigo de $1981 \mathrm{em}$ que, influenciada por Agee e recorrendo a Foucault, refleti sobre meu trabalho de campo nas periferias de São Paulo?.

As questões principais e persistentes que têm requerido minha atenção desde o final dos anos 1970 até o presente são diferentes daquelas enfrentadas por antropólogos que fazem pesquisa em sociedades que não são as suas próprias. Central entre elas é o fato de que a pesquisa nas periferias urbanas da minha cidade é estruturada por inevitáveis diferenças de classe, além de hierarquias de gênero e raça. Num país altamente desigual como o Brasil, a pesquisa nas periferias tem significado até muito recentemente ${ }^{10}$ o encontro entre pesquisadores das classes médias e altas e moradores pobres. Trabalho de campo para mim foi - e continua sendo - marcado e constituído por essa desigualdade social, que também se traduz em hierarquias raciais e de gênero. Não existiam culturas diferentes. O contexto que cria nossas diferenças é

8. "It seemed to me that the fetish of ethnography and fieldwork remained more or less in place. The question of who was authorized to speak and what forms that speech (and its written transformation) should take could well have moved the discussion in potentially important directions. Unfortunately, it tended to provide a naïve credence to subjectivity and ultimately did not pay the transformational dividends that had been anticipated and heralded. In very American fashion, the attention to the subject of knowledge was turned into confessional debates about the "self," precisely at the moment when it seemed that the challenge was to invent modes of thinking and research that while not being positivist nonetheless sought ways to undertake a process of going beyond the (given) self".

9. Esse artigo foi escrito antes que eu conhecesse o livro de Rabinow sobre o trabalho de campo e as críticas à antropologia clássica que já estavam sendo formuladas na época por James Clifford, George Marcus, Michael Fisher, e George Stocking, entre outros. Seguia, contudo, as discussões que se desenvolviam na USP ao redor das reflexões de Ruth Cardoso, Eunice Durham e seus alunos. Ver sobretudo: Cardoso, 1986.

10. Discuto adiante as mudanças recentes. 
apenas um: aquele que produz a nós todos como desiguais. Não existe nada exterior a esse contexto. No meu caso, o trabalho de campo também significou as iniciativas de uma mulher (jovem nos anos 1980) em contextos marcados pelo desprezo por mulheres independentes e profissionais e, até recentemente, pela crença corrente nas periferias de que o homem era o chefe e a voz da família. Em outros termos, no campo como eu o encontrei, uma pesquisadora e seus colaboradores já são sempre co-constituídos como desiguais. Isso não significa que relações de colaboração e de aprendizado sejam impossíveis, apenas que elas são configuradas de uma certa maneira. De fato, as relações estabelecidas no campo são bastante complexas e envolvem não apenas desigualdade, mas também respeito e esforços genuínos de escutar e entender através das diferenças.

As análises de Foucault $(1979,1980)$ sobre as dinâmicas de poder envolvidas na produção de conhecimento permitiram que eu encontrasse maneiras de considerar os mecanismos de produção de discursos de verdade e da autoridade que mesmo uma mulher jovem - mas educada e que se apresentava como pesquisadora e estudante universitária - exercia nas periferias. Minha questão central no artigo de 1981 era: quais são os mecanismos que levam as pessoas nesses bairros periféricos a falarem comigo, fornecerem informações, produzirem discursos verdadeiros em resposta às minhas perguntas, a me receberem em suas casas e se tornarem minhas amigas? Minhas credenciais da universidade e a minha classe social certamente estão no cerne da equação, mas também estão lá meu claro interesse em escutar e aprender, minha humildade, meu reconhecimento de sua dignidade, que não poderia ser eclipsada pela sua pobreza, e o respeito que sempre demonstrei em relação a todas as pessoas acostumadas a só encontrarem desrespeito em seus encontros com pessoas das classes mais altas. Nos anos 1980 e até os anos 2000, não encontrei ninguém que clara e diretamente mostrasse antagonismo à minha presença, que se recusasse a falar comigo, a responder às minhas perguntas, a fazer um esforço para produzir informações que elas julgavam ser verdadeiras. Recentemente, as coisas mudaram significativamente, tornando as dinâmicas de poder presentes no trabalho de campo palpáveis.

Novos contextos, novas referências

Desde o final dos anos 1980 até agora, os tipos de pesquisas conduzidas por antropólogos mudaram substancialmente, exigindo novas referências e exacerbando as questões não resolvidas sobre produção de conhecimento que já vinham sendo articuladas pelas críticas dos anos 1980-1990. As principais mudanças ocorreram nas seguintes áreas: studying up; estudando a contemporaneidade, sobretudo em 
cidades; e estudando processos globais ${ }^{11}$. Primeiro, houve mudanças nos objetos de investigação, com uma significativa proliferação de studying up, para usar uma expressão famosa de Laura Nader (1969), ou seja, estudos em que o trabalho de campo é feito em laboratórios, firmas de tecnologia digital, corporações, tribunais etc., e em diálogo com jornalistas, burocratas, planejadores, arquitetos, advogados etc. Essa tendência é especialmente evidente nos Estudos de Ciência e Tecnologia (sTs, Science and Technology Studies). Segundo, houve um aumento dos estudos urbanos, não apenas aqueles feitos em cidades, mas sobretudo aqueles que tomaram formações urbanas, arquitetura, planejamento e sistemas de regulação como seus objetos de investigação. Os estudos sobre/em periferias urbanas que são importantes no Brasil fazem parte dessa tendência e geraram muitas reflexões sobre a prática antropológica. Terceiro, houve uma questão significativa de escala, na medida em que antropólogos passaram a tentar entender processos globais e a indagar como poderiam adaptar seus métodos e teorias a estudos nessa escala. As discussões sobre multi-sited ethnographies (Marcus, 1995) são exemplares dessa tendência. Em todos esses casos, o trabalho de campo transformou-se em algo totalmente novo, bem diferente do tipo de experiência que Rabinow tinha tido numa vila no interior do Marrocos, e ele mesmo fez parte dessa transformação ao iniciar suas pesquisas de campo em laboratórios de biotecnologia. O trabalho de campo descolou-se do estudo de culturas e passou a ser mais experimental, fragmentado, interdisciplinar e negociado em novos termos. $\mathrm{O}$ estudo da contemporaneidade requer novos parâmetros e novas reflexões. A articulação de representações e as concepções de autoria mudam. Em boa medida isso acontece porque os tipos de interlocutores mudam radicalmente, primeiro devido aos estudos com experts, cientistas, profissionais etc., depois por causa do foco nas sociedades e nos contextos em que vivem os antropólogos. Referências aos “outros" perderam o sentido, do mesmo modo que muitas das exigências de distanciamento ainda mantidas na etnografia tradicional.

Mas o que essas mudanças significam em termos da concepção dos encontros que acontecem no trabalho de campo? O que elas significam em termos da construção de significados produzidos por antropólogos e seus interlocutores através de todos os tipos de desigualdades e diferenças sociais? O que elas significam em termos de autoria? É claro que formações de desigualdade e poder sempre foram a moldura inevitável que constitui essas relações, mas elas agora adquirem outros contornos e não podem mais ser deixadas de lado ou ignoradas. Pesquisadores não são mais

11. Certamente está além do escopo deste artigo caracterizar em detalhes essas novas áreas e perspectivas de pesquisa. Assim, não vou me referir a autores específicos que são importantes na formulação dessas novas perspectivas e na produção de trabalhos definitivamente inovadores. Uma lista curta seria seguramente arbitrária, e é impossível fornecer aqui uma lista completa. 
os agentes mais poderosos nas relações de produção de conhecimento. Pense, por exemplo, na descrição de Kaushik Sunder Rajan das suas negociações com corporações de biotecnologia para tornar seu trabalho de campo viável (2006, cap. 6). Elas envolveram vários ciclos de autorizações, seu projeto ser analisado por advogados, o controle de entrevistados pelos seus supervisores, acordos escritos determinando o escopo das conversas, limites à publicação dos resultados e, obviamente, muitas recusas diretas em participar. Todas elas constituem novos enquadramentos para o trabalho de campo. Nessas condições, não apenas a autoridade e o poder do antropólogo são deslocados, mas também fica difícil conceber as relações no campo em termos de interação pessoal e rapport, como os antropólogos costumavam fazer. As novas condições não tornam a pesquisa impossível, mas com certeza a estruturam de maneiras novas. Sunder Rajan teve que contratar advogados e assinar um contrato legal com seus entrevistados para viabilizar sua pesquisa. Acho que há muito a ser dito acerca da ideia de contratos e vou retornar a ela mais tarde no texto.

Não é sempre que antropólogos estão nessa posição em que sua legitimidade e seu poder estão diretamente em xeque. Na maioria das situações, quem sabe, eles continuam a ter bastante poder e capacidade de moldar as relações que se estabelecem na pesquisa. Mas isso não os impede de serem críticos em relação às situações em que se encontram e de buscarem alternativas que minimizem desigualdades e desequilíbrio de poder. Mesmo em situações de estudo em relações de grande desigualdade, similares às de Agee, passam a conceber suas relações no campo não como a do poderoso extrator de informações, mas como de alguém que entra em diálogos e intercâmbios. $\mathrm{O}$ contrato é uma forma de reger as relações entre pesquisadores e pesquisados, mas não é a única nem a mais frequente. Muitos antropólogos passaram a investir na ideia de colaboração, sobretudo em pesquisas em contextos transnacionais. As novas relações de pesquisa exigiam novas referências e um novo vocabulário. A noção do informante foi assim pouco a pouco posta de lado.

\section{Repensando colaborações}

Ideias de colaboração na produção do trabalho antropológico já tiveram várias formulações no contexto da onda crítica que se iniciou ao redor de Writing culture e continuam a ser reformuladas. Um ponto de partida de toda discussão é a rejeição da noção positivista de que existe uma realidade exterior a ser captada e representada por quem a vive, e a aceitação da ideia de que o que acabamos chamando de dados em pesquisa social qualitativa é o resultado de encontros, trocas, diálogos, elaborações em conjunto, em que pesem as desigualdades entre as partes. Não existe produção de conhecimento no campo sem colaboração. Não existe significado, dado, que 
esteja pronto lá fora à espera de ser coletado. Qualquer sentido ou dado que possa existir nas ciências sociais é criado em contextos de diálogo e colaboração. Ou seja, não há dado sem colaboração, embora ela possa ser pensada de várias maneiras. Uma delas é a que aparece nas reflexões de Rabinow (1977), para quem antropólogo e marroquinos colaboram, uns aprendem com os outros, ampliam seus horizontes. No entanto, para Rabinow, parte do papel do antropólogo era o de treinar os informantes em como colaborar, uma ideia não muito frequente em anos mais recentes e ainda próxima à da etnografia clássica. $\mathrm{O}$ antropólogo tinha que conduzir seus informantes a produzirem discursos e informações que pudessem ser importantes para o projeto dele - um processo obviamente sempre precário e sujeito a surpresas.

No Brasil, mais ou menos a partir da mesma época - final dos anos 1970 - e no contexto da consolidação da antropologia urbana e do que Eunice Durham uma vez chamou de "uma nova e intrigante etnografia de nós mesmos" (1986, p. 17), formularam-se reconsiderações sobre essa coprodução de dados no campo. Em 1979, num artigo sobre a interpretação da fala em pesquisa antropológica, Ruth Cardoso ([1979] 2011) argumentou que, para se entender o que seria a interpretação, era necessário ter clareza sobre aquilo que se interpretava ${ }^{12}$. Alguns anos mais tarde, no mesmo ano em que se publicou Writing culture, Ruth Cardoso (1986) organizou o volume $A$ aventura antropológica, que reuniu várias reflexões sobre a antropologia urbana que se fazia no Brasil a partir dos anos 1970 e os desafios metodológicos que ela representava, reflexões que se haviam produzido de maneira paralela às discussões americanas e não necessariamente em diálogo com ela. Em sua contribuição para esse volume, Ruth Cardoso volta à questão da natureza dos dados qualitativos. Discursos captados por entrevistas não podem ser tratados como simples evidência, argumenta. Dados qualitativos resultam de uma interação comunicativa específica entre pesquisador e entrevistado e são, portanto, uma coprodução resultante de circunstâncias específicas. A relação que gera os dados é, em geral, uma relação entre pessoas que são estranhas entre si e colaboram para a produção de conhecimento.

A relação intersubjectiva não é o encontro de indivíduos autônomos e autossuficientes. É uma comunicação simbólica que supõe e repõe processos básicos responsáveis pela criação de significados e grupos. É nesse encontro entre pessoas que se estranham e que fazem um movimento de aproximação que se podem desvendar sentidos ocultos e explicitar relações desconhecidas (Cardoso, 1986, p. 103).

12. Ver também meus comentários sobre os textos de Ruth Cardoso a respeito do método. Caldeira, 2011, especialmente pp. 24-31. 
Essas ideias vinham se articulando há anos entre os antropólogos urbanos brasileiros. Em "Uma incursão pelo lado 'não respeitável' da pesquisa de campo", e como parte dessas elaborações, afirmei essa coprodução dos dados num processo colaborativo e tentei refletir sobre as desigualdades que moldavam essa coprodução. A questão que me forçava a refletir sobre o tipo de colaboração que produzia os dados era o que, em nossa sociedade, legitima, sustenta e naturaliza a prática da pesquisa de campo. Recorrendo a Foucault, argumentei:

Creio, em suma, que é a associação entre poder e saber científico que possibilita e sustenta a relação que se estabelece entre o pesquisador e o informante, que dá a um condições de exercer seu trabalho (seu poder) e a outro a ideia da obrigatoriedade e da necessidade de se sujeitar. Isso implica ver, portanto, que a relação que se estabelece no campo entre pesquisador e seu informante é uma relação de poder: relação em que um requer um depoimento e o outro se vê na contingência de responder; em que um pede que tudo seja dito nos mínimos detalhes, e o outro se esforce por dizer a verdade que, no entanto, só o primeiro poderá revelar (Caldeira, 1981, p. 334).

O resultado não é a impossibilidade da relação nem da produção de dados, mas a peculiaridade dessa produção, constituída por relações de força e marcada por ambiguidade, resistência, subterfúgios, mas também por desabafos, pedidos de ajuda, trocas e esforço por produzir discursos verdadeiros. Mas é claro que dispositivos de saber-poder têm várias dimensões e vão bem além da academia. Relações de classe, de gênero e de raça também são estruturantes. Comecei a explorar alguns desses aspectos nesse artigo, mas sigo me sentindo impelida a tomá-los em consideração e a avaliar as maneiras pelas quais mudaram nesse período em que trabalhei como uma pesquisadora de campo. Volto a isso num momento.

Mas não foi apenas no Brasil e no campo da antropologia urbana que se pensou sobre questões de colaboração, coprodução e desigualdade. Muitos antropólogos têm pensado sobre isso. George Marcus $(2008,2018)$ refletiu em várias ocasiões sobre colaboração e sugeriu vários experimentos e interpretações. Suas reflexões são referências para muitas das discussões sobre colaboração. Marcus cunhou nos anos 2000 uma expressão que passou a ser importante em toda a discussão sobre colaboração. Para ele, antropólogos e seus colaboradores no contexto das novas pesquisas seriam epistemic partners (parceiros epistêmicos).

Uma vez que o sujeito "reflexivo" é agora o único tipo de sujeito que o antropólogo encontra, e onde a reflexividade do sujeito existe ou se sobrepõe ao mesmo universo intelectual que informa o pesquisador (necessariamente tornando o sujeito seu parceiro epistêmico, a modo 
de dizer, na condução da pesquisa), então "colaboração" substitui o tropo de "aprendizado" (ou suas alternativas) como definidora da "cena" do encontro do trabalho de campo (Marcus, 2008, p. 7, ênfase minha) ${ }^{13}$.

As mudanças contextuais que fizeram Marcus sugerir a noção da parceria epistêmica foram basicamente duas. Primeiro, a imersão de antropólogos nos STS, em que seus parceiros eram cientistas, advogados, jornalistas etc., agentes envolvidos eles mesmos na produção de alguma forma de conhecimento etnográfico. Não era exatamente o mesmo contexto vivido por Sunder Rajan, por exemplo, em que os informantes eram quase antagonistas à pesquisa, mas ainda assim era um contexto de studying up. Segundo, a imersão de antropólogos em projetos de pesquisa formulados na base de identificação política e ativismo envolvendo pesquisadores e seus colaboradores. Nesse contexto, o projeto político transformaria todos em parceiros. Esses projetos proliferaram a partir dos anos 1980, nos Estados Unidos, no Brasil (sobretudo no contexto da transição democrática e do auge dos movimentos sociais urbanos), e em vários outros lugares. Como observa Marcus (2008, p. 7), esse era também o contexto em que as formas neoliberais se disseminam e em que a possibilidade de financiamento muitas vezes conduzia à formação de parcerias, por exemplo, entre ONGs e pesquisadores.

Em suma, já temos aqui várias versões de colaboração, o termo que passa a ser preferido para pensar a relação entre pesquisadores e seus parceiros de pesquisa. Elas incluem: a coprodução de dados no contexto mais clássico em que o antropólogo treina seus colaboradores para que ajudem a produzir os dados que precisa; a parceria na formulação de todo o projeto de pesquisa, como no caso dos STS; e a produção de conhecimento no contexto de parcerias políticas e de ativismo. Entre essas opções, a mais igualitária seria a segunda, mas esses parceiros epistêmicos seriam em geral quase sempre acadêmicos e não existiria grande diferença social estruturando as relações, embora pudesse haver grandes diferenças de poder, como no caso do estudo de Sunder Rajan.

Tomás Sánchez Criado e Adolfo Estalella (2018) recentemente adicionaram uma nova possibilidade, que eles denominam colaboração experimental e que em muitos sentidos é uma elaboração da noção de parcerias no caso de interdisciplinaridade (como no contexto dos STS):

13. "[...] $]$ once the 'reflexive' subject is now the only kind of subject the anthropologist encounters, and where the reflexivity of the subject exists in, or overlaps with, the same intellectual universe that informs the researcher (necessarily making the subject his epistemic partner, so to speak, in the conduct of research), then 'collaboration' replaces the trope of "apprenticeship" (or its alternatives) as defining the 'scene' of fieldwork encounter". 
[...] ao invés de noções de solidariedade e equidade, para nós colaboração teria o formato de situações tentativas nas quais os antropólogos seriam levados a reciclar suas técnicas tradicionais (notas e entrevistas) ou seriam envolvidos em intervenções intensas no campo, às vezes trabalhando de maneira harmoniosa com seus parceiros, ou às vezes se chocando com eles. Nessas situações, o método etnográfico é re-equipado com novas infraestruturas, espaços de produção de conhecimento, formas de relações e modos de representação. Vista dessa maneira, a colaboração não seria a tradicional condição constitutiva de qualquer trabalho de campo caracterizada por uma relação assimétrica [...], nem uma estratégia deliberativa irrigada por compromissos políticos e éticos [...]. Ao contrário, seria uma forma de engajamento em explorações epistêmicas com aqueles anteriormente descritos como informantes, e agora reconfigurados como parceiros epistêmicos. Chegamos à concepção desse processo como algo que abala o primado da observação na etnografia e revela outras práticas epistêmicas no trabalho de campo (2018, p. 10) $)^{14}$.

Os exemplos que eles exploram são, por exemplo, os de etnógrafos desenhando páginas na internet para facilitar o trabalho de projeto e ativismo de um grupo de colaboradores, num processo de coformulação e resolução de problemas práticos (como a construção de uma rampa móvel para o uso de pessoas em cadeiras de rodas).

A substituição da noção de informantes pela de colaboradores e depois pela de parceiros epistêmicos é certamente significativa e reduz o papel dos etnógrafos de campo a uma dimensão bem menos pretensiosa do que a dos antropólogos clássicos dando voz aos outros e desvendando suas culturas. Mas não resolve todas as desigualdades sociais e disparidades de poder ainda envolvidas na pesquisa de campo. $\mathrm{Na}$ verdade, a prática dessas parcerias acaba criando outras questões importantes, que tanto Marcus quanto Sánchez Criado e Estalella não consideram. São questões que nos remetem outra vez às reflexões de Agee sobre desigualdade e poder.

Não foram muitos os antropólogos que refletiram abertamente sobre as relações com seus parceiros, sobretudo quando elas envolvem diferenças sociais significativas.

14. "[...] rather than notions of solidarity and equity, for us collaboration takes the form of tentative situations in which anthropologists appear to be prompted to repurpose their traditional techniques (taking notes and interviewing) or are drawn into intense interventions in the field, at times working smoothly with counterparts, at other times clashing with them. In these situations, the ethnographic method is re-equipped with new infrastructures, spaces of knowledge production, relationship forms and modes of representation. Taken this way, collaboration would not be the traditional constitutive condition of any fieldwork characterized by an asymmetric relationship [...], nor a deliberate strategy infused by political and ethical commitments [...]. Rather, it would be a form of engaging in joint epistemic explorations with those formerly described as informants, now reconfigured as epistemic partners. We have come to think of this process as one that unsettles the observational convention of ethnography and reveals other epistemic practices in fieldwork". 
Uma das autoras que refletiram sobre isso e levaram a discussão a novas direções foi Richa Nagar ${ }^{15}$. Ao fazer isso, ela voltou à questão de autoria. Tanto Marcus (2008, 2018) e Sánchez Criado e Estalella (2018) quanto Dattatreyan e Marrero-Guillamón (2019, p. 222), ao discutirem alternativas para a prática antropológica, mencionam a coautoria e a coprodução de dados e de eventos como alternativas para modos mais igualitários de produção de conhecimento, pelo menos na sua publicação - ideia essa que já era cara à geração de Writing culture. Em um artigo de 2003, Richa Nagar já tinha argumentado que suas colaboradoras, que aparecem no artigo não como coautoras, mas como consultoras, não estavam interessadas em coautoria. Nagar sugere que uma concepção mais radical e complexa de colaboração tem que necessariamente problematizar noções de que colaboração pode ser traduzida em termos de coautoria; de que falar para audiências acadêmicas é uma prioridade; e de que todos os envolvidos em um processo de pesquisa estariam interessados em garantir direitos de propriedade intelectual e reconhecimento de audiências acadêmicas ( $\mathrm{p}$. $378)^{16}$. Segundo Nagar, os produtos de uma colaboração podem às vezes ser escritos juntos, mas isso não é algo necessário.

O desafio para geógrafas pós-coloniais e feministas, então, é conceber cruzamentos de fronteiras que estejam comprometidos em formar novas parcerias colaborativas com atores acadêmicos e não acadêmicos em "outros" universos, em todos os sentidos do termo - parcerias nas quais questões sobre como poder e autoridade seriam compartilhados não podem ser respondidas de antemão, mas são imaginadas, disputadas e resolvidas através do próprio processo colaborativo $(2003, \text { p. } 379)^{17}$.

15. Agradeço a Malini Ranganathan pelo diálogo acerca dos nossos dilemas com trabalho de campo e por indicar as referências das discussões de Richa Nagar.

16. Num artigo em coautoria, Koni Benson e Richa Nagar, ambas feministas, refletem sobre a questão da colaboração e indagam se ela poderia ser uma prática de resistência tanto na antropologia quanto na história oral no contexto de pesquisas com ONGs. Elas argumentam que é imperativo que feministas criem "novas metodologias colaborativas que possam simultaneamente resistir à 'de-radicalização da política feminista' tanto na academia crescentemente corporatizada, quanto no setor das onGs cada vez voltado às agências fundadoras, profissionalizado e identificado com o estado (2006, p. 581)" ("new collaborative methodologies that can simultaneously resist the 'deradicalization of feminist politics' in the increasingly corporatized academy as well as in the increasingly donor-driven, professionalized, and state-identified NGO sector").

17. "The challenge for postcolonial and feminist geographers, then, is to conceptualise bordercrossings that are committed to forming collaborative partnerships with academic and non-academic actors in "other" worlds, in every sense of the term - partnerships in which the questions around how power and authority would be shared cannot be answered beforehand, but are imagined, struggled over and resolved through the collaborative process itself". 
Em suma, as reflexões de Nagar são especialmente provocativas porque ela separa colaboração de coautoria e separa autoria de textos e representações do processo de produção de conhecimento, o que no caso da pesquisa etnográfica envolve não só pesquisadores e colaboradores, mas várias outras pessoas. Além disso, ela insiste que a colaboração pode resultar em vários produtos em diferentes formatos e que cada um deles pode ter diferentes formas de autoria. Finalmente, e a meu ver crucialmente, ela insiste que questões de poder e de autoridade não podem ser resolvidas de antemão, mas têm que ser enfrentadas e resolvidas durante o próprio processo colaborativo.

Novas referências para a produção de conhecimento em contextos de desigualdade

Questões de poder e de autoridade na produção de pesquisa mudam constantemente e, portanto, precisam sempre ser renegociadas. Nos últimos anos, algumas transformações em cidades e nas relações socioespaciais que elas abrigam, bem como em modos de circulação de informação, alteraram as condições de produção de conhecimento social especialmente a partir de periferias urbanas. Gostaria de mencionar três dessas mudanças e refletir sobre suas consequências.

A primeira mudança refere-se à proliferação de tecnologias digitais para a circulação de informação. Essa é uma mudança estrutural, sobre a qual não vou poder me estender muito, já que exigiria em si mesma um estudo separado. É amplamente sabido como a normatização da internet provoca mudanças nos mais diferentes aspectos da vida social. Um desses aspectos é o deslocamento do monopólio de circulação e regulação da informação acadêmica. Se no passado instituições acadêmicas e revistas científicas e editoras tinham em grande medida o poder de regular o que circulava como produção científica, hoje isso já não é mais o caso. Artigos podem ser publicados na internet em formato de pdf sem nenhuma forma de controle por autoridades acadêmicas. Qualquer artigo recusado por revistas científicas pode alcançar significativa audiência e obter respeitável número de citações ao ser publicado em páginas da internet não reguladas por autoridades científicas. Quando a revista Fortune se negou a publicar o ensaio de James Agee, foram necessários cinco anos para que ele aparecesse sob o formato de livro - e Agee e Walker eram ambos profissionais reconhecidos. Hoje, o pdf poderia estar disponível numa questão de horas, e as mídias sociais poderiam ser acionadas para chamar atenção para o texto e sua rejeição. Informações circulando sob o formato de blogs alcançam audiências muito mais amplas do que aquelas divulgadas em revistas acadêmicas. Ou seja, se para carreiras acadêmicas a regulação de publicações e o controle sobre o que é publicado podem ser ainda relevantes, para a circulação de resultados de pesquisa, de interpretações, de opinióes e de colaborações, essa regulação está se tornando cada 
vez menos relevante. Basicamente, qualquer texto pode circular sob a forma de pdf na internet. $\mathrm{O}$ volume do que circula também mudou radicalmente, e manter critérios de relevância está cada vez mais difícil. Se no passado alguns centros de poder e de regulação podiam controlar quase toda a circulação de informações, hoje isso não é mais possível. Consequentemente, questões de autoria e de legitimidade mudam.

Num ensaio de 1970 intitulado “O que é um autor?”, Michel Foucault argumentou que nas sociedades modernas o autor é basicamente um regulador de significado ${ }^{18}$.

O autor não é uma fonte indefinida de significações que preenchem uma obra; o autor não precede as obras; ele é um certo princípio funcional graças ao qual, na nossa cultura, se delimita, se exclui, e se seleciona; em suma, graças ao qual se impede a livre circulação, a livre manipulação, e a livre composição, decomposição, e recomposição da ficção [...]. O autor é, portanto, a figura ideológica graças à qual se marca a maneira pela qual nós tememos a proliferação de sentido ([1970] 1984, pp. 118-119) ${ }^{19}$.

Nesse texto, que obviamente não considerava a proliferação da circulação de discursos em plataformas digitais, Foucault já antevia a mudança do que ele chamou de "função do autor" e dos modos de existência dos discursos. Nas sociedades modernas, essa função seria basicamente a de fazer circular a verdade e conferir legitimidade a discursos. Foucault admitia nesse texto que essa configuração poderia estar mudando, que a função do autor poderia desaparecer, e que os discursos passariam a funcionar de acordo com um outro modo, ainda dentro de um sistema de contenção, mas um sistema a ser determinado.

Todos os discursos, não importa seu status, forma, valor, e qualquer que seja o tratamento a que serão submetidos, iriam então se desenvolver no anonimato de um murmúrio (119, minha ênfase $)^{20}$.

18. Estou trabalhando com o texto de Foucault publicado no Foucault Reader e que segue uma versão apresentada na Universidade de Buffalo em 1970. Esta é uma versão condensada da conferência que ele proferiu em 1969 e que foi publicada anteriormente no Bulletin de la Societé Française de Philosophie. Para uma análise mais aprofundada sobre a maneira pela qual Foucault concebe o autor, ver: Adorno, 2012.

19. "[...] the author is not an indefinite source of significations which fill a work; the author does not precede the works; he is a certain functional principle by which, in our culture, one limits, excludes, and chooses; in short, by which one impedes the free circulation, the free manipulation, the free composition, decomposition, and recomposition of fiction $[. .$.$] The author is therefore the ideologi-$ cal figure by which one marks the manner in which we fear the proliferation of meaning".

20. "All discourses, whatever their status, form, value, and whatever the treatment to which they will be subjected, would then develop in the anonymity of a murmur". 
Com a proliferação das plataformas digitais e a possibilidade de circulação infinita de discursos desafiando o controle do sentido, poderíamos estar chegando então ao cenário imaginado por Foucault em que não faria mais diferença saber quem é o autor, e em que não mais tememos a proliferação de significado. Todos produzimos murmúrios. Nas plataformas digitais - mas não só nelas -, como os discursos são largamente não regulados e mesmo não reguláveis (a não ser pelas grandes corporações proprietárias das plataformas digitais e seus algoritmos), e como existem cada vez menos posições de autoridade a partir das quais se podem ancorar discursos que tenham legitimidade, não só todos os tipos de discurso podem circular sem regulação, mas sobretudo as fake news proliferam e circulam amplamente, sem que se possa com certeza distinguir o que é fake e o que não é. Qualquer coisa e tudo vira informação. Todos os discursos praticamente se equivalem.

Mas é claro que esse é apenas um lado das transformações na circulação e regulação de discursos. Há ainda muitos espaços em que a produção de discursos e de conhecimento se insere claramente em disputas de poder e de legitimidade, em tentativas de estabelecer o que deve ser tomado como crível, mas não como no passado. Vivemos em contextos em que se podem desestabilizar modos existentes de organização do público e seus significados e em que debates sobre o lugar da fala denotam tentativas de reinventar a regulação de discursos.

Duas importantes mudanças sociais permitem articular algumas reflexões sobre regulação/circulação de discursos e retornar às questões do trabalho de campo, da colaboração e da autoria. Haveria outras mudanças a considerar, mas vou me deter nestas uma vez que meu trabalho de campo tentou investigá-las e, assim, elas me permitem retornar às reflexões acima. Elas são a importante produção cultural originada nas periferias de São Paulo e o acesso de jovens desses espaços às universidades, sobretudo aos cursos de ciências sociais.

Desde os anos 1990, as periferias de São Paulo têm promovido uma intensa produção cultural, que se iniciou no hip-hop e teve as mais diversas expressões, como o rap, o grafite, a pixaçã $o^{21}$, os saraus e a literatura marginal, o vídeo periférico etc. A história dessa imensa e intensa produção cultural não tem como ser contada/contida neste texto. Correndo o risco de simplificar muito, diria que em seu conjunto essa produção conseguiu afetar a circulação e a produção de discursos a partir das periferias e sobre elas e deslocar sua presença tanto no espaço público da cidade quanto no da produção acadêmica. Toda essa produção criou formas alternativas de produção e circulação de discursos que ganharam legitimidade e visibilidade, apesar de acontecerem em circuitos não regulados pelas instituições que até então

21. Adoto a grafia de pixação com " $\mathrm{x}$ ", seguindo o uso de seus produtores. 
conseguiam estabelecer o que deveria ser entendido como arte, literatura, música, vídeo etc. Talvez a forma mais radical desse deslocamento seja a pixação, que usurpa o espaço público da cidade, transformando-o em espaço de articulação de discursos daqueles que até então não tinham um discurso público. É especialmente significativo que os discursos produzidos pela pixação sejam simultaneamente onipresentes na cidade, extremamente visíveis e em grande parte ilegíveis. Daí sua transgressão: a pixação constituiu o espaço público da cidade sem permitir que sua intervenção seja regulada; ela continua a ser não assimilável e transgressiva ${ }^{22}$.

Desde o início dos anos 2000, tenho realizado pesquisas sobre a nova produção cultural articulada a partir das periferias. As relações estabelecidas no campo e as condições de pesquisa foram substancialmente diferentes daquelas que eu havia conhecido até então e discutido em trabalhos anteriores e sobretudo em "A incursão pelo lado 'não respeitável' da pesquisa de campo". Se anteriormente eu não tinha encontrado resistência e recusas, agora elas ficavam claras. As condições que moldam as possibilidades do trabalho de campo estavam mudando, pois as condições sociais nas periferias estavam se transformando, e o grupo que eu estava interessada em estudar fazia parte da vanguarda dessas mudanças. Desde o início dessa pesquisa, interpretei as recusas e as condições impostas às minhas interações com os produtores culturais como sinais da profundidade das mudanças. Eles não mais precisavam se submeter às minhas solicitações de entrevistas: podiam simplesmente me ignorar, se quisessem. Aos poucos, fui mudando minha concepção sobre o campo. Se nas pesquisas anteriores partia do pressuposto de que as interações e as entrevistas iriam ocorrer na casa dos entrevistados ou nos seus espaços de moradia, nas pesquisas com os produtores culturais entendi que nossa interação, se possível, iria ocorrer em espaços públicos e seria moldada por várias restrições. Abandonei completamente o dogma da observação participante e o imperativo de tentar viver a experiência cotidiana dos grupos estudados, que se tinham embutido na minha mente como sinônimo de pesquisa etnográfica. Não frequentaria suas casas, não conheceria suas famílias, muitas vezes não saberia suas histórias de vida nem mesmo seus nomes completos: não compartilharia seu cotidiano e não tentaria viver a experiência de sua vida e o dia a dia de sua produção: o que eu estudava era sua intervenção no espaço público, e isso não requeria nenhuma vivência de suas vidas privadas. Eu só me relacionaria com suas personas públicas. Tentei aprender o máximo possível sobre sua produção cultural e, para isso, ouvi muito rap e fui a muito show de rap, assisti muitos saraus e tentei ler o mais que pude as suas publicações, percorri a cidade documentando grafites e pixaçôes e tentei aprender sua linguagem. Mas nunca tentei participar do processo

22. Em Caldeira, 2012, analiso a pixação, o grafite e novas formas de circulação em São Paulo. 
de criação de suas intervenções - nem pensar em ir grafitar e pixar! Uma vez que os limites foram ficando claros tanto para mim quanto para os produtores culturais que estabeleceram vários deles, as entrevistas foram sendo possíveis. Todas aconteceram em espaços públicos - bares, centros culturais, galerias -, sempre escolhidos por eles. E todas com o entendimento de que o foco seria a produção cultural e sua circulação no espaço público. Foram trocas interessantes, entre pessoas que conversavam de modo mais igualitário. Eu entrava como autora, presenteava uma cópia do meu livro Cidade de muros, e os entrevistados também entravam como autores, mostravam seus raps, seus livros, seus grafites, suas pichações, suas coleções de imagens, sua presença na internet, e discutíamos sobre a cidade e suas desigualdades e sobre suas visões como produtores culturais e criadores de poderosas intervençôes no espaço público. Os produtores culturais falavam com paixão sobre seu trabalho e queriam que eu entendesse como era produzido e o que significava para eles. Senti que eles tinham interesse em que eu os ouvisse e entendesse o que faziam. Tinham também interesse em saber sobre o que eu pensava sobre seu trabalho.

Essa pesquisa sobre produção cultural das periferias estendeu-se por mais de uma década, e durante esse período as mudanças tanto nas dinâmicas sociais da cidade quanto nas possibilidades de trabalho de campo foram ficando cada vez mais claras. Mais de duas décadas depois de eu ter iniciado minhas pesquisas nas periferias, experimentava uma mudança na dinâmica de poder no trabalho de campo. Foi um alívio deixar que os produtores culturais estabelecessem a agenda da pesquisa e parte das regras do jogo, ao invés de simplesmente se sujeitarem às minhas. Essas mudanças eram uma clara indicação de quanto a cidade e a sociedade tinham mudado e de como um grupo de rapazes jovens (sim, a maioria dos produtores culturais, sobretudo no grafite e na pixação, são homens) estavam transgressivamente tornando essas mudanças palpáveis no espaço da cidade. Havia uma significativa transformação tanto na maneira pela qual os espaços do centro eram ocupados por pessoas de diferentes classes sociais, quanto na cultura de subserviência que havia contribuído para manter as camadas de trabalhadores silenciadas e distantes quando interagindo com pessoas das elites. Poder realizar a pesquisa de campo em termos que não envolviam essa subserviência e podiam incluir a marcação de distância e rejeição foi uma experiência reveladora das mudanças dos tempos.

Outra mudança muito significativa que ocorreu nas últimas décadas e que afetou as condições do trabalho de campo nas periferias foi a entrada da primeira geração de jovens nascidos e vivendo nas periferias na universidade (uma condição compartilhada por muitos dos produtores culturais). Como é sabido, o acesso à educação no Brasil mudou muito nas últimas décadas. A porcentagem de jovens entre $18 \mathrm{e}$ 24 anos sem educação básica caiu de 58\% para 16\% no período 1995-2014. Ao 
mesmo tempo, a porcentagem daqueles com educação secundária subiu de 12 para $33 \%{ }^{23}$. O acesso à educação superior subiu entre todos os grupos sociais, embora ainda seja muito limitado entre os grupos de renda mais baixa. Apesar disso, os efeitos desse acesso, mesmo que ainda limitados, são significativos. No Jardim das Camélias, bairro em que faço pesquisas de campo desde 1978, a porcentagem de moradores com educação universitária subiu de zero a 6\% entre 1980 e 2013. Isso foi possível graças a uma série de programas de ação afirmativa e cotas e à expansão de universidades federais.

É inegável que esse acesso à universidade significa uma abertura de possibilidades. Mas muitas vezes, ao contrário do que se pensa, essas não são possibilidades profissionais. Há um claro descompasso entre o curso universitário e a vida profissional. As pessoas sempre estudam e trabalham, mas em geral essas coisas não se complementam. Mesmo as pessoas formadas na USP, acabam se vendo sem alternativas no mercado de trabalho e aceitando trabalhos de telemarketing ou outras formas de trabalho uberizado, ou seja, temporário, superexplorado e sem vínculo (ver Abílio, 2020). Essa é uma das maiores fontes de frustração e indignação desses jovens que fazem enormes esforços para se formarem - junto com as muitas histórias de humilhação que eles têm a contar sobre sua experiência de frequentar salas de aula em companhia de jovens das classes médias. Então, o que a universidade acaba oferecendo de mais poderoso é exatamente a possibilidade de acesso a novos modos de pensar e sobretudo de se organizar. É a possibilidade de formar redes, de se engajar em coletivos, de fazer parte da criação e do consumo de uma cena supervibrante de produção cultural e ativismo.

Quando iniciei minha última pesquisa sobre transformações no que chamei de formações de vida coletiva nas periferias, decidi que o principal grupo com o qual gostaria de conversar era o dos jovens nascidos nas periferias e que estavam protagonizando essas mudanças: entrando nas universidades, criando outros tipos de famílias, redefinindo papéis de gênero, formando coletivos e denunciando o racismo estrutural que sempre os tinha vitimado. Quando comecei a formar uma equipe de pesquisadores em 2018, decidi que queria que meus colaboradores fossem parte dessa primeira geração de jovens moradores das periferias que tinham chegado às universidades e se formado em ciências sociais. Ao final, a equipe de seis membros tinha cinco com esse perfil e foi formada por Katia Ramalho Gomes, Danielle Regina de Oliveira, Luiz Paulo Ferreira Santiago, Artur Santoro, Mayara Amaral dos Santos e Renata Adriana de Souza. Todos

23. Todos os dados de Balbachevsky et al., 2019. "A porcentagem dos jovens dos dois quintis inferiores alcançando o [ensino superior] subiu de 2\% em 1995 para 12\% em 2014”. Enquanto isso, entre os jovens do quintil superior, a porcentagem frequentando o ensino superior subiu de $21 \%$ para $61 \%$ (p. 13 ). 
eles tinham experiência anterior em participação em coletivos. Durante vários meses, nós nos reunimos semanalmente para discutir o andamento da pesquisa. Essas reuniões aconteciam na Fundação Getulio Vargas, após as aulas de um curso sobre pesquisa qualitativa do qual eles também participavam junto com outros alunos da FGV, da USP e do Mackenzie ${ }^{24}$. Tanto o curso quanto as reuniões de pesquisa foram marcados por tensões significativas. Essa primeira geração de intelectuais e acadêmicos das periferias está disposta a problematizar a produção de conhecimento social e, como acontece com estudantes sul-africanos, pretende descolonizar a universidade e o trabalho de campo. Eles estavam interessados tanto em problematizar a relação com seus colegas de outros grupos sociais, quanto em transformar os modos pelos quais se produz conhecimento sobre os espaços em que vivem, desequilibrando hierarquias há muito estabelecidas e abrindo novas perspectivas de crítica, análise e conceptualização. Esse processo emergente e em formação é sem dúvida tenso e ainda longe de estar totalmente delineado mas, a meu ver, é um dos aspectos mais significativos desta pesquisa.

Questões sobre o significado da produção de conhecimento sobre as periferias feitas por seus próprios moradores, indagações sobre a relação dessa produção com outras formas de conhecimento sobre as periferias e problematização da relação dos pesquisadores comigo, a coordenadora do projeto, foram constantes nas reuniões semanais de pesquisa. Questionamentos sobre a posicionalidade dos pesquisadores em relação, de um lado, a pessoas das periferias que se disponibilizaram a participar da pesquisa ou se recusaram a fazê-lo e, de outro, em relação à coordenadora foram recorrentes e nem sempre de fácil solução. Foi no contexto dessas discussões que forjamos relações de colaboração e tomamos decisões que permitiram o andamento da pesquisa. Formulamos um contrato escrito, assinado por todos, em que concordamos que os dados que estávamos produzindo coletivamente durante a pesquisa seriam compartilhados e poderiam ser utilizados individualmente por cada um de nós em nossos escritos e trabalhos futuros, claro que com o devido crédito. Éramos definitivamente parceiros epistêmicos, embora estivesse claro que essa parceria não era harmônica. Decidimos conjuntamente que a pesquisa seria um espaço para os pesquisadores desenvolverem sua própria voz e autoria. Essa autoria teria que ser problematizada para revelar nossas tensões e perspectivas diferentes. Este artigo é parte do meu esforço de enfrentar algumas das tensões e das questões sobre as quais me sinto obrigada a pensar. Escrevemos um relatório final em que cada um se encarregou de um capítulo tratando do tema em que havia centrado seu interesse de

24. Durante o primeiro semestre de 2018, fui pesquisadora visitante com apoio da Fapesp junto à FGV e ao NEV-USP. A pesquisa de campo para esse projeto de pesquisa teve apoio da Fundação Tide Setubal, e todos os colaboradores foram pagos. 
pesquisa. Também concordamos que seria importante explorar espaços e modos de publicação que fossem além da academia e acessíveis às pessoas que haviam colaborado nas entrevistas. Assim, publicamos uma série de textos de autoria individual no Le Monde Diplomatique e produzimos uma série de podcasts para a divulgação dos resultados entre as redes de coletivos e moradores das periferias. Os podcasts foram feitos sob a forma de um diálogo entre dois pesquisadores ${ }^{25}$. Nessas plataformas, nossas autorias e vozes são equivalentes.

Nenhuma dessas decisões poderia ter sido prevista a priori. De fato, questões de poder, de desigualdade, de autoridade e de autoria não podem ser resolvidas de antemão, mas têm que ser negociadas durante o próprio processo da pesquisa, como sugeriu Richa Nagar (2003). A ideia do contrato pareceu ser bastante produtiva, pois permitiu uma certa garantia de que ninguém era de fato "dono" da pesquisa e que todos os dados eram compartilhados e acessíveis a todos numa plataforma virtual. Não é certamente o mesmo tipo de contrato que Sundar Rajan teve que formular com seus entrevistados, mas a meu ver teve a função de tornar possível a continuidade da pesquisa em um contexto de bastante questionamento. O contrato deu alguma clareza sobre as bases nas quais as trocas estavam sendo realizadas e sobre o que se espera da colaboração. Também separamos a produção dos dados, que foi sobretudo coletiva e compartilhada, da autoria dos produtos da pesquisa, que decidimos que seria individual. O que foi compartilhado pode não ter correspondido à totalidade do que foi produzido, pois alguns pesquisadores foram claros sobre o fato de que não estavam compartilhando tudo. Mas o que foi compartilhado tornou-se acessível a todos. Não consideramos a questão de coautorias, a não ser nos diálogos dos podcasts. Preferimos privilegiar a elaboração de autorias individuais.

Essas decisões obviamente não resolveram todas as questões. Mas acho que elas tiveram um importante papel: chamam atenção para os problemas que estruturam a produção do conhecimento em condições marcadas por desigualdades, tornando-os visíveis, evidentes, acessíveis e, espera-se, mais tratáveis. As desigualdades - de classe, de raça, de gênero, de poder - continuam a ser estruturantes na pesquisa, porque são basicamente estruturais na sociedade e não podem ser resolvidas apenas no contexto de um projeto. Contudo, elas podem ser deslocadas, enfrentadas. Elas não foram resolvidas, mas não impediram a produção da pesquisa. Ao serem problematizadas de forma direta, recriam e reformulam as condições de produção do conhecimento e, portanto, a qualidade dos dados produzidos. A autoria precisa ser

25. Os artigos foram publicados na edição brasileira do Le Monde Diplomatique e os podcasts na sua plataforma Guilhotina. Todos os artigos e podcasts podem ser acessados em: https://diplomatique.org. $\mathrm{br} /$ especial/periferiasp/. 
trabalhada para representar as tensões e desigualdades encontradas no campo. Ela precisa ser crítica e humilde.

O processo de pesquisa não apenas é aberto, como incerto. O que se tem que aceitar é a incerteza e a fragilidade dos discursos, a indeterminação dos lugares, apesar de todos seus determinantes. Partir dessa indeterminação e dessa fragilidade é o que abre possibilidades para experimentos, transgressões, e invenções que deslocam questões e podem produzir novo conhecimento, mesmo que sempre contestável. Afirmar a fixidez dos lugares, impor explicações já prontas para as muitas desigualdades, enquadrar as relações em moldes predeterminados significa fechar possibilidades. A questão é deixar existirem as possibilidades de disputas de narrativas, de superposição de narrativas, de embate de discursos, de incerteza na produção do conhecimento. Essas são possibilidades que costumamos atribuir a um espaço público democrático.

\section{Referências bibliográficas}

AвíLIo, Ludmila Costhek. (2020), “Uberização e juventude periférica”. Novos Estudos, 39 (3): 579-597.

Adorno, Sérgio. (2012), “O autor nos escritos de Foucault: entre o discurso e a morte”. Jornal de Psicanálise, 45 (82): 113-128.

Agee, James \& Evans, Walker. ([1941] 1969), Let us now praise famous men. Boston, Houghton Mifflin Co.

Balbachevsky, Elizabeth; Sampaio, Helena \& Andrade, Cibele Yahn de. (2019), "Expanding access to higher education and its (limited) consequences for social inclusion: The Brazilian experience". Social Inclusion 7 (1): 7-17.

Benson, Koni \& Nagar, Richa. (2006), "Collaboration as resistance? Reconsidering the processes, products, and possibilities of feminist oral history and ethnography”. Gender, Place and Culture, 13 (5): 581-592.

Caldeira, Teresa Pires do Rio. (1981), "Uma incursão pelo lado 'não respeitável' da pesquisa de campo". In: Ciências Sociais Hoje, 1 (Trabalho e Cultura no Brasil). Recife/Brasília, ANPOCS/CNPq, pp. 332-54.

Caldeira, Teresa Pires do Rio. (1988), "A presença do autor e a pós-modernidade em antropologia”. Novos Estudos Cebrap, 21: 133-157.

Caldeira, Teresa P. R. (2011), “Apresentação: Ruth Corrêa Leite Cardoso: a intelectual e seu tempo”. In: Ruth Cardoso - Obra Reunida. São Paulo, Mameluco, pp. 8-38.

Caldeira, Teresa P. R. (2012), "Imprinting and moving around: New visibilities and configurations of public space in São Paulo”. Public Culture 24 (2): 385-419.

Caldeira, Teresa P. R. (2021). “Fieldwork: problems we are still required to think”. HaU: Journal on Ethnographic Theory, 11 (2): 720-725. 
CARdoso, Ruth C. L. ([1979] 2011), "Notas para discussão". In: Ruth Cardoso - Obra Reunida, org. de Teresa P. R. Caldeira. São Paulo, Mameluco, pp. 197-202.

CArdoso, Ruth C. L. (1986), (org.). A aventura antropológica: teoria e pesquisa. Rio de Janeiro, Paz e Terra.

Clifford, James. (1983), “On ethnographic authority”. Representations, 2: 132-143.

Clifford, James \& Marcus, George. (eds.). (1986), Writing culture: The poetics and politics of ethnography. Berkeley, University of California Press.

Dattatreyan, Ethiraj Gabriel e Isaac Marrero-Guillamón. (2019), "Introduction: Multimodal anthropology and the politics of invention”. American Anthropologist, 121 (1): 220-228.

Denby, David. (2006), "A famous man. The collected works of James Agee”. The New Yorker, January $9^{\text {th }}$, https://www.newyorker.com/magazine/2006/01/09/a-famous-man.

Durham, Eunice Ribeiro. (1986), “A pesquisa antropológica com populações urbanas: problemas e perspectivas". In: CARDOSO, Ruth C. L. (org.). A aventura antropológica: teoria e pesquisa. Rio de Janeiro, Paz e Terra.

Foucault, Michel. (1979), Microfísica do poder. Rio de Janeiro, Graal.

Foucault, Michel. (1980), Power/Knowledge: Selected interviews and other writings, 19721977. Colin Gordon, editor. Nova York, Pantheon Books.

Foucault, Michel. ([1970] 1984), “What is an author?”. In: Rabinow, Paul, editor. Foucault reader. Nova York, Pantheon Books, pp. 101-121.

Geertz, Clifford. (1973), The interpretation of cultures. Nova York, Basic Books.

Marcus, George. (1995), "Ethnography in/of the world system: The emergence of multi-sited ethnography”. Annual Review of Anthropology, 24: 95-117.

MARCUs, George. (2008), “The end(s) of ethnography: social/cultural anthropology’s signature form of producing knowledge in transition”. Cultural Anthropology. 23 (1): 1-14.

Marcus, George. (2018), "Foreword. Collaboration mode 3: a found condition of anthropological field research today... and what might be made of it”. In: EsTALELLA, A. \& SÁNCHEZ Criado, T. (eds.). Experimental collaborations. Nova York, Berghahn Books, pp xi-xvi.

NADER, Laura. (1969), “Up the anthropologist: perspectives gained for studying up”. In: HyMES, Dell, editor. Reinventing anthropology. Nova York, Pantheon, pp. 284-311.

NAGAR, Richa. (2003), “Collaboration across borders: moving beyond positionality”. In consultation with Farah Ali and Sangatin women's collective. Singapore Journal of Tropical Geography, 24 (3): 356-372.

Poovey, Mary. (1998), A history of the modern fact: problems of knowledge in the sciences of wealth and society. Chicago, University of Chicago Press.

Rabinow, Paul. (1977), Reflections on fieldwork in Morocco. Berkeley, University of California Press. Rabinow, Paul. (2002), "Midst anthropology's problems”. Cultural Anthropology, 17 (2): 135-49. Rabinow, Paul. (2007), Reflections on fieldwork in Morocco. $30^{\text {th }}$ anniversary edition. Berkeley, University of California Press. 
SÁnchez Criado, Tomás \& Estalella, Adolfo. (2018), "Introduction. Experimental collaborations". In: Estalella, Adolfo \& SÁnchez Criado, Tomás, editors. Experimental Collaborations. Nova York, Berghahn Books, pp. 1-30.

STOckIng JR., George, W. (1983), “The ethnographer's magic: fieldwork in British anthropology from Tylor to Malinowski”. In: STOCKING JR., George W., ed., Observers observed: Essays on ethnographic fieldwork. Madison, University of Wisconsin Press.

Sunder Rajan, Kaushik. (2006), Biocapital: The constitution of postgenomic life. Durham, NC: Duke University Press.

\section{Resumo}

Desigualdade e legitimidade: problematizando a produção de conhecimento social

Nos últimos quarenta anos, as ciências sociais e sobretudo a antropologia passaram por mudanças significativas. Neste artigo, reflito sobre questões e dilemas que dizem respeito à maneira pela qual se produzem pesquisas sociais, sobretudo ao trabalho de campo em situações marcadas por grandes desigualdades. Dizem também respeito à questão de como conceber as representações dos achados dessas pesquisas e a autoria. E, finalmente, concernem às possibilidades de circulação dos discursos.

Palavras-chave: Pesquisa social e desigualdade; Trabalho de campo; Autoria; Regulação de discursos.

\section{Abstract}

Inequality and legitimacy: problematizing the production of social knowledge

In the last 40 years, the social sciences and especially anthropology have gone through substantial changes. In this article, I reflect on questions and dilemmas related to the way of producing social research, especially through fieldwork in situations marked by large inequalities. These questions also relate to how to conceive of the representation of the findings and to authorship. Finally, they relate to the possibilities of the circulation of discourses.

Keywords: Social research and inequality; Fieldwork; Authorship; Regulation of discourses.

Texto recebido em 02/10/2021 e aprovado em 22/10/2021.

DOI: $10.11606 / 0103-2070 . t s .2021 .191135$

Teresa Pires do Rio Caldeira é antropóloga e professora no Departamento de Planejamento Urbano e Regional na Universidade da Califórnia, Berkeley. E-mail: tcaldeira@berkeley.edu. 